\title{
Hemodynamics Monitoring in Sport Using Hemodynamic Monitor for Sport Training Planning
}

\author{
Anna Shishkina, Natalia Tarbeeva, Oksana Alimpieva, Anastasia Berdnikova, \\ Alena Tarbeeva and Tatiana Miasnikova \\ Institute of Physical Education, Sport and Youth Policy, Ural Federal University, Mira Street, Ekaterinburg, Russia
}

\begin{abstract}
Keywords: Cardiovascular System, Hemodynamic Indicators, Training Process, Athletes' Hemodynamics, Training and Testing.

Abstract: The study stresses the meaning of the physiological measures that are obtained with the functional diagnostics devices and how these values can be used in coaching sportsmen. Methods: Hemodynamic monitor was used for monitoring hemodynamics and heart function of athletes $(n=305)$ with different fitness levels. Active orthoclinostatic tests and antiorthostatic tests with passive body position changing were carried out with hemodynamics measurements recorded. Results: The most informative indicators and indices of heart function for high performance sport and their values at rest were detected. Along with common hemodynamics indicators (HR, SV, CO, EDV, blood pressure, etc.) the possibility of using correlation rhythmogram in coaching was studied. The correlation rhythmogram "cloud" dependence on athletes' fitness level was revealed in transient during active orthoclinostatic test.
\end{abstract}

\section{INTRODUCTION}

The success in sport training and performance is determined by the adequate functioning of the cardiovascular system and by the conformity of system blood flow to physical work intensity. Too intensive physical work and mental stress disrupts the regulatory systems interaction, leads to fatigue and impaired immunity and causes non-specific defence mechanisms changing homeostasis and reducing the effectiveness of professional sport activity.

Current functional diagnostics provides the opportunities to study various indicators that are important in sports activities. Regular measurements allow estimating how different training load influences the athlete's body.

There are several aims of athletes' functional diagnostics:

- Assessing current functional state;

- Detecting early signs of physical stress and overtraining;

- Evaluating the effectiveness of the training process;

- Determining appropriate ways for further individual training planning.
Many devices are currently available for measuring human function (Critoph, 2013; Magder, 2014; Rowland, 2003; Newman, 1999; Cooke, 1998, etc). Understanding the utility of these devices requires an understanding of the determinants.

Functional hemodynamics monitoring is a rapidly evolving field whose pluripotential is just now being realized (Pinsky, 2014). The aim of our research was twofold. Firstly, it was necessary to study the possibility of using the hemodynamic monitor for hemodynamics assessment in sport research. Secondly, we investigated the use of the device in sport coaching. Not only is it important to measure a great number of different indicators, but also to interpret the data for effective sport training planning.

\section{DEVICE AND TECHNOLOGY DESCRIPTION}

The hemodynamic monitor MARG 10-01 "Microlux" used in emergency and operation rooms was made in Chelyabinsk (Russia). The device functioning is based on such noninvasive methods of hemodynamic monitoring as impedance 
cardiography and spectrophotometry. Compact (250x140x90 mm) and light (less than $2 \mathrm{~kg}$ ) MARG 10-01 measures and displays data of the following areas: electrocardiogram monitoring (ECG), pulse oximetry monitoring, reography and central hemodynamics monitoring, blood pressure and temperature monitoring.

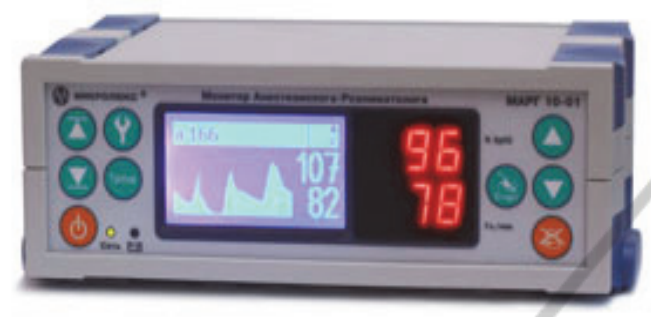

Figure 1: The hemodynamic monitor MARG 10-01 "Microlux".

ECG monitoring includes a graphic representation of the current ECG-signal for visual assessment.

Hemodynamics is described by four general indicators: volemia, inotropy, vascular tone, chronotropy. The above-mentioned indicators are shown as a percentage of normal values. The ranges of normal values of indicators are counted by the program taking into account the patient examination features (gender, age, weight, breast and neck circumference, distance between electrodes, hemoglobin, etc.). The deviations of more than $25 \%$ are considered too high/low.

Volemia is the amount of circulating blood which corresponds to the vessel volume. Inotropy is myocardial contractility power. Vascular tone may be normal, dilated or constricted.

A correlation rhythmogram is a set of points which have coordinates defined by two adjacent cardiointervals values $\left(R_{i}\right.$ and $\left.R_{i+1}\right)$. Normal "sinus arrhythmia" forms the image of "cloud" (fig.2).

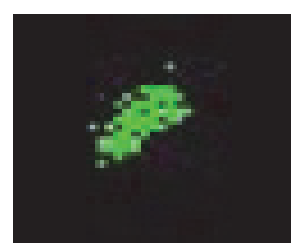

Figure 2: Correlation rhythmogram.

The method of heart beat distribution is highly sensitive to a sudden RR-intervals duration change. It allows seeing extrasystoles, rhythm disturbances, signs of different diseases (for instance, acute respiratory diseases) and other changes in cardiorhythm.

Central hemodynamic indicators are presented in four groups: perfusion, preload, afterload, contractility and left ventricular activity.

Perfusion is the movement of fluid (i.e. blood) through an organ or tissue in the vessels as a result of pressure changes. Perfusion is composed of the following indicators:

- Stroke volume is the volume of blood ejected by the left ventricle in each systole. In healthy people it is $60-80 \mathrm{ml}$ at rest;

- Cardiac output is the volume of blood flowing through the cross section of the aorta and pulmonary trunk per minute. 3.4 litres is the normal value for healthy people;

- Stroke index is the ratio of stroke volume to body surface area;

- Cardiac index is the ratio of cardiac output to the body surface area in square metres.

Preload is a measure of left ventricular wall effort at the end of diastole. Preload is represented by:

- End-diastolic volume is the maximum amount of blood received in left ventricle at the end of diastole;

- End-diastolic index is the ratio of end-diastolic volume to the body surface area in square metres

Afterload is a measure of left ventricular wall effort during systole. Afterload is represented by the following indicators:

- The index of total peripheral resistance;

- Stroke index of total peripheral resistance

Contractility and left ventricular activity includes the following indicators:

- Contractility index (acceleration index) is an integral component of contractile ability of the heart; - Ejection fraction is the relative volume of blood ejected from the left ventricle during contraction, in healthy individuals it is $58 \%$;

- Index of left ventricle activity is a generalized measure of the work of the left ventricle;

- Stroke index of left ventricle activity.

Measuring Methods. For the experiment a patient (athlete) was in supine position on the tilted table in the silent room with constant air temperature $\left(22^{\circ} \mathrm{C}\right)$. Before recording all subjects were at rest in supine position during 10 minutes. 8 pregelled ECG electrodes $\mathrm{Ag} / \mathrm{AgCl}$ were attached as shown in figure 3. All measured indicators of the central hemodynamics were automatically registered by the programme by beat-to-beat record. 


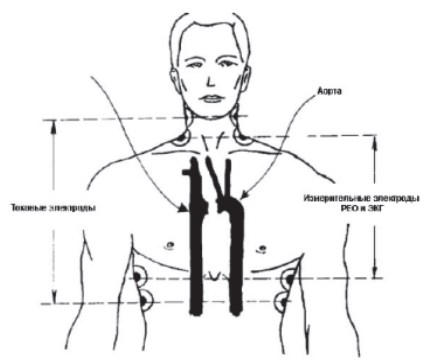

Figure 3: Scheme of electrodes attachment.

\section{EXPERIMENTS}

We assume that regular informative athletes' functional diagnostics should be the basis for the planning of the training process.

\section{Experiment 1}

Participants and Methods. From May 2010 to May 2014 a large group $(n=305)$ of athletes from different kinds of sport (cross country skiing, biathlon, track and field, triathlon, swimming, Greco-Roman wrestling, sport games, etc.) aged from 10 to 50 was examined. Among the participants there were athletes of various skill levels from novice $(n=38)$ and intermediate level $(n=239)$ to advanced athletes $(\mathrm{n}=28)$, including those who had achieved international level.

By novice we mean those athletes who engaged in sport not longer than 3 years ago. Intermediate athletes have 4-7 years of serious training experience in the chosen kind of sport. Special attention was given to representatives of endurance kinds of sport (cross country skiing, track and field and biathlon).

Results And Discussion. To investigate the functional state of the athletes we chose the most informative for sports activity hemodynamic indicators.

Heart rate (HR) is the most accessible and informative indicator of the development of athletes' cardiorespiratory system. HR at rest for adult representatives of endurance cyclical kinds of sport is less than 55 beats/min. The lowest value recorded during the experiment was 28 beats/min. - in the well-trained female who has been practising crosscountry skiing for more than 30 years has such. An athlete's HR at rest that is over 55 beats/min indicates insufficient heart function for elite sport and/or muscular system domination over the cardiovascular development preventing success in endurance sport. The best representatives of "aerobic" sport with a duration of competitive activity over $20 \mathrm{~min}$, including sports games, also have low heart rate. For elite athletes with a predominance of speed and power parameters in competitive activities a heart rate within $60 \pm 5$ beats/min is permissible. High pulse of the latter may not be the limiting factor in competitive activity; however, it does not allow an athlete to cope with a large amount of physical load required for high performance sport.

The stroke volume (SV) values of untrained adult men do not exceed $100 \mathrm{ml}$, well-trained adult females have $120 \pm 15 \mathrm{ml}$, male athletes $-140 \pm 17 \mathrm{ml}$, while the best representatives of sports requiring endurance show SV $180 \pm 14 \mathrm{ml}$ (Seluyanov, 2002). These indicator values should be a reference point in examining athletes.

Cardiac output (CO) is the indicator of cardiac systolic function and is equal to HR multiplied by $\mathrm{SV}$. Increasing $\mathrm{SV}$ and $\mathrm{CO}$ during long term exercise is one of the main effects of endurance training. At the same time the growth of $\mathrm{CO}$ should occur due to SV rise, but not due to heart rate rise.

Large end diastolic volume (more than $190 \mathrm{ml}$ ) provides sufficient stroke volume and cardiac output and is the guarantor of good tolerance to high intensity work load in training and competitive activities.

An ejection fraction changes from 60 to 65 and serves as an indicator of fitness level and the intensity of the training process. Regular extensive endurance training does not increase ejection fraction (Scharhag, 2002). The highest values of ejection fraction are observed in sport game players. In cyclical kinds of sport ejection fraction increases correspondingly to the athlete's fitness level enhancement to the competitive activity. It is explained by analysing the physical load structure per year: the closer the competition, the more intensive workouts are used, the higher the ejection fraction.

Breathing rate. It is considered that special training of the respiratory system is not required for well-trained athletes as it develops itself during physical training. However, 12,13\% of the examined athletes have higher than normal breathing rate. The normal number of breaths per minute in adults is correlated with the heart rate as 1:4. Breathing and hemodynamics are interdependent processes (Donina, 2011). In case of high breathing rate in athletes you should first check blood hemoglobin, hematocrit and lung capacity, secondly, exclude post training acidosis and, thirdly, fermentopathy and heart disease. For enhancing respiratory function in healthy athletes with high 
breathing rate breathing exercises, altitude training or partly limited air inhaling during training (for instance, breathing through nose), intermittent hypoxic training, etc may be used.

For finding out the correlation between hemodynamic indicators and sport performance thirteen well-trained skiers (men) were included in the next study. The subjects' age was from 15 to 17 . All of them had 5-6 years of training and competition experience. Each subject was well rested before testing during the previous 24 hours. All athletes in measurement were at rest in the supine position.

We determined normal values (mean \pm standard deviation) for each hemodynamic indicator in the group of athletes. Then we held correlation analysis between indicators and sport performance ranking of skiers in Russia. Statistical analysis showed significant correlation between athletes' performances and stroke volume $(\mathrm{r}=0.77$; $122 \pm 22 \mathrm{ml})$, cardiac output $(\mathrm{r}=0.61 ; 6.8 \pm 1.61)$, enddiastolic volume $(\mathrm{r}=0.76 ; 193 \pm 34 \mathrm{ml})$, stroke index $\left(\mathrm{r}=0.82 ; 69 \pm 11 \mathrm{ml} / \mathrm{m}^{2}\right)$, heart index $(\mathrm{r}=$ $\left.0.65 ; 3.9 \pm 0.91 / \mathrm{m}^{2}\right)$, end-diastolic index $(\mathrm{r}=0.81$; $110 \pm 17 \mathrm{ml} / \mathrm{m}^{2}$ ) and stroke index of left ventricle work $(r=0.62 ; 74 \pm 14)$. There was no correlation between performance and heart rate $(57 \pm 8$ beats $/ \mathrm{min})$, ejection fraction $(63 \pm 2 \%)$ and index of left ventricle activity $(4.2 \pm 1.0)$.

Thus such indicators as stroke volume, cardiac output and end-diastolic volume showed athlete's conditions and they might be predictors of fitness level and competition results. But these indicators do not take into account athletes' body size and muscle mass.

Such indicators as heart rate, ejection fraction and index of left ventricle work do not correlate with performance, however they show the heart work quality and can be good indicators of overexertion. All the above-mentioned indicators can be used for monitoring athletes' function during seasons.

It is known that cardiorespiratory system functions are considered important factors of success in endurance sports. In force-velocity sports, martial arts and sport games coaches sometimes underestimate the level of cardioendurance. However, our study showed that important hemodynamic indicators (SV, EDV) of medal holders in World and European championships were always high.

Age-average stroke volume and end diastolic index of excellent sportsmen in our research are shown in fig. 4.

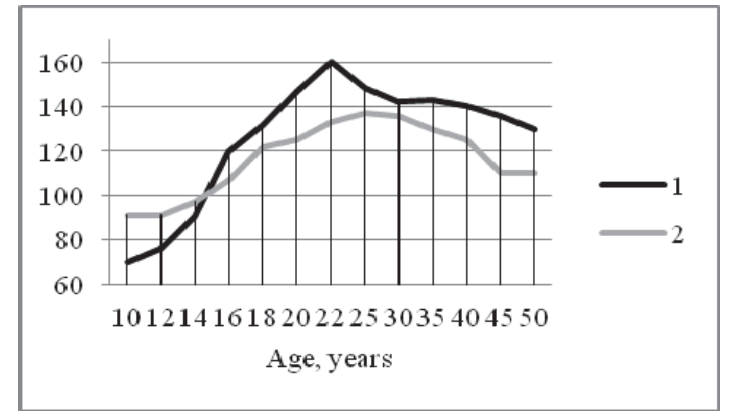

Figure 4: Hemodynamics in excellent athletes of different age. $1-\mathrm{SV}, \mathrm{ml} ; 2-\mathrm{EDI}, \mathrm{ml} / \mathrm{m}^{2}$.

It was proved that cardiac output was twice lower in juvenile rats than in adults $(106+/-5$ $\mathrm{ml} / \mathrm{min}$ ), but cardiac (heart) index was not different among groups (Delp, 1998). We found that in human athletes the cardiac output may be equal in child and adult, the average stroke volume increases from childhood till the age of 22, then it smoothly decreases (fig.4). But it stays higher than in untrained people. End diastolic index (fig. 4) was used to show the relative hemodynamics changes. In rats and untrained people it stays constant with age. Due to intensive sport activity EDI increases significantly. Thus we can conclude that regular sport training causes the adaptation changes in athletes' central hemodynamics.

It is possible to increase stroke volume and EDV by special low intensive $(\mathrm{HR}=120 \pm 10)$ long lasting training sessions (Seluyanov, 2002) within a month or two or by high-intensity interval training. But due to training growth of SV and EDV may be limited and partly predetermined genetically. Determining SV and EDV in youth allows predicting athletic success and prospects for the sport.

\section{Experiment 2}

Since stroke volume is not a stable indicator (it changes during physical load, stays higher afterwards in recovery period and may be increased as a result of training process) we organized the experiment with the purpose to analyse the changes in central hemodynamics of cross country skiers during the macrocycle and in the process of longterm training (3 macrocycles).

Participants and Methods. In the period from May 2011 to August 2013 a group ( $=28)$ of welltrained cross country skiers aged from 14 to 20 years was examined.

The measurements were provided 4 times per year: 1 - off-season (May), 2 - the $1^{\text {st }}$ part of preparatory period (June - August), 3 - the $2^{\text {nd }}$ part 
of preparatory period (September - November), 4 competition period (December - April).

Results and discussion. The dynamics of heart rate at rest of athletes in supine position during macrocycle tend to significantly decrease from the beginning of the off-season till the start of the competitive period (fig. 5-7). Such dynamics had place in each subsequent macrocycle in cross country skiing. At the same time there were positive dynamics for all indicators. Heart rate at rest for three-year period has changed in the same period of training (May) to $68 \pm 4,4$ to $52,2 \pm 3,3$ beats/min in the group of cross country skiers (fig.5).

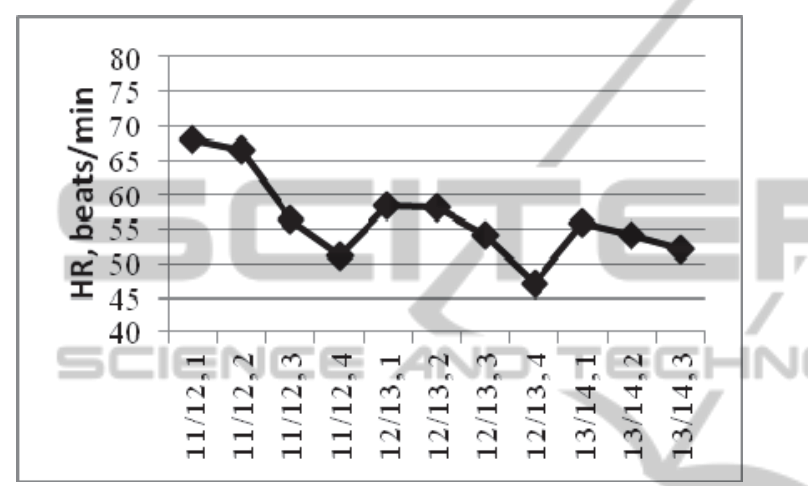

Figure 5: Heart rate dynamics during three macrocycles.

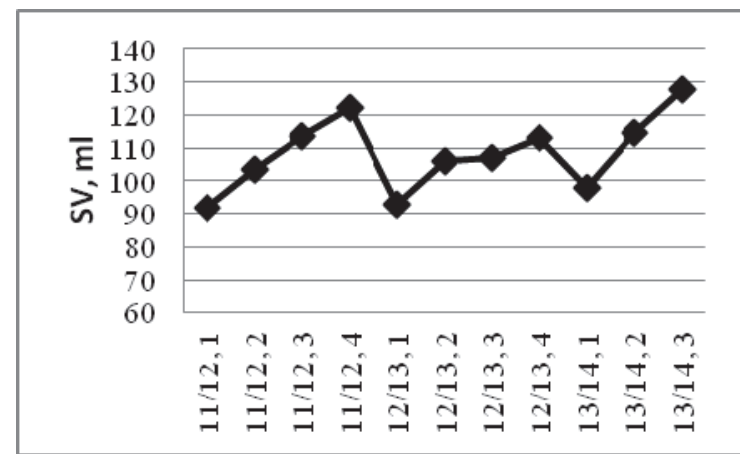

Figure 6: Stroke volume dynamics during three macrocycles.

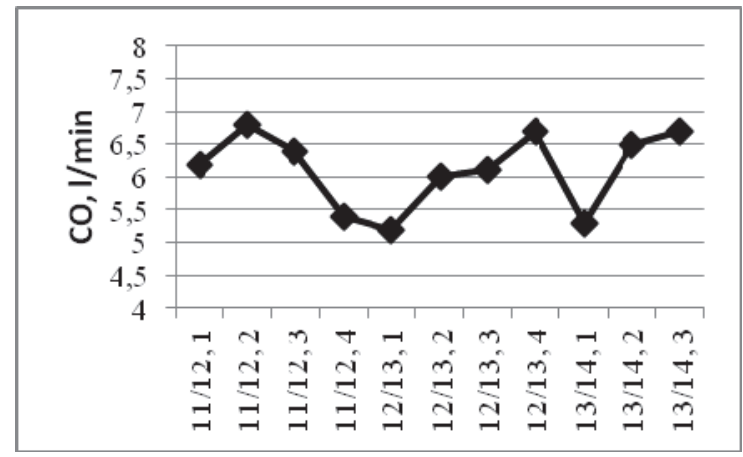

Figure 7: Cardiac output dynamics during three macrocycles.
In the examined group of skiers SV dynamics for three macrocycles had a stable growth trend. Within three macrocycles there is a gradual increase of the $\mathrm{CO}$ from 6,2 to $6,71 / \mathrm{min}$ on average in the group.

Thus, in the process of long-term training of cross country skiers the central hemodynamics indicators such as stroke volume, cardiac output and cardiac index are rising but heart rate is appropriately decreasing. This is due to increased levels of fitness and adaptation to physical work. The study also revealed SI, CO and CI increases and decrease in heart rate within the macrocycle for all periods except off-season time. There was an increase in HR and a slight decrease in SV, leading to lowering $\mathrm{CO}$ and SI. It proved the ineffectiveness of the training process for cross country skiers in the off-seasons.

\section{Experiment 3A.}

The aim of the study was to determine the effects of athletes' organism adaptation to the environment and to physical activity.

Participants and Methods. 20 athletes (12 females and 8 males, cross country skiers) aged from 10 to 20 with different fitness levels were undergoing an active orthoclinostatic test (supine position1 during $3 \mathrm{~min}-$ standing during $3 \mathrm{~min}-$ supine position 2 during $3 \mathrm{~min}$ ). All the above mentioned indicators and indices were registered automatically with the software of the Hemodynamic monitor MARG 10-01 (beat-to-beat record). Special attention was given to correlation rhythmogram in different patients' body position and in transient periods (from supine1 to standing and from standing to supine2 position).

Results and Discussion. Orthoclinostatic test allows estimating participation of parasympathetic and sympathetic system in heart rate regulation and speed and quality of this regulation.

Quality of transition can be estimated by the action of physiological systems regulation. The regulation time and the maximum deviation of the adjustable value from the initial value are the main indicators of quality of regulation (Stickland, 2006). The lower each of the mentioned hemodynamics indicators is, the higher the quality of regulation in transient.

Comparison of organism reactions during active orthoclinostatic tests revealed that athletes with 1 or 2 years of sport experience demonstrate a strong reaction of heart rate in transient into standing position (table 1). After returning to supine position2 the heart rate of novices in sport was much higher than in initial supine position1 at rest. Positive 
changes in adaptation as a rule appeared at the end of the third year of regular sport training: the heart rate in supine position2 $\left(\mathrm{HR}_{3}\right)$ tended to $\mathrm{HR}_{1}$ at rest (table 1). The group of sportsmen with 4-7 years of sport experience have an adequate adaptation reaction in orthoclinostatic test similar to the reaction to physical workload: the HR rise is moderate.

Advanced athletes have professional sports reaction in active orthoclinostatic test: $\mathrm{HR}_{3}$ is even lower than $\mathrm{HR}_{1}$. The correlation rhythmogram orthoclinostatic test: the longer the experience in sport is, the less R-R intervals dispersion at rest ("cloud" and even "dot") and in transient ("bisectrix") and the shorter the period of HR getting stabilized.

Thus, according to athletes' organism orthoclinostatic test reaction indicators (HR changes and "cloud" sizes in the correlation rhythmogram) one can judge the fitness level of young sportsmen and adjust the physical workload in correspondence proves and specifies HR reaction in the

to athletes' physiological readiness to train hard.

\section{Experiment 3B}

Antiorthostatic test is a test method of diagnostics of the cardiovascular system and its response to changes from the supine horizontal position to the head-down tilt. Antiorthostatic test allows estimating the athlete's functional state with a reliable validity because humans do not have adaptive mechanisms for this position. This method is mainly used in clinical medicine.

Materials and Methods. Examined group $(n=14)$ of female athletes (swimming) is aged 17-18. All of them have intermediate sport level.

Antiorthostatic tests with passive body position changes and hemodynamics measurements recording was carried out in the following stages:

1. Supine (horizontal) position at rest during $3 \mathrm{~min}$ : 2. Passive (by the tilted table) transition to the Trendelenburg position (fig.7) with a tilt angle of $30^{\circ}$.

Table 1: Athletes orthoclinostatic test peculiarities in dependence of sport experience.

\begin{tabular}{|c|c|c|c|c|}
\hline $\begin{array}{c}\text { Athletes' } \\
\text { experience }\end{array}$ & Supine position 1 & $\begin{array}{l}\text { Post transition period } \\
1-2\end{array}$ & Supine position 2 & Heart rate dynamics \\
\hline \multirow[b]{2}{*}{$\begin{array}{l}\text { Novices with } \\
1-2 \text { years of } \\
\text { sport } \\
\text { experience }\end{array}$} & $\mathrm{HR}_{1}=65$ & $\mathrm{HR}_{2}=86$ & $\mathrm{HR}_{3}=70$ & \multirow{2}{*}{ 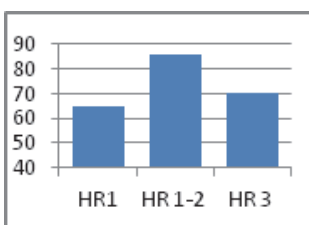 } \\
\hline & : & •: : : : : & 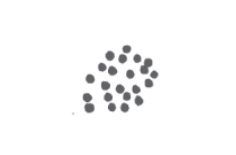 & \\
\hline \multirow[b]{2}{*}{$\begin{array}{l}\text { Novices of } \\
\text { the third year } \\
\text { of sport } \\
\text { experience }\end{array}$} & $\mathrm{HR}_{1}=63$ & $\mathrm{HR}_{2}=80$ & $\mathrm{HR}_{3}=60$ & \\
\hline & •• & $\because$ & ఊ० & $\begin{array}{lllllll}80 & & & & \\
70 & & & & \\
60 & & & & \\
50 & & & & & \\
40 & & & & \\
4 R 1 & \text { HR 1-2 } & \text { HR3 }\end{array}$ \\
\hline \multirow[b]{2}{*}{$\begin{array}{l}\text { Intermediate } \\
\text { trainees } \\
\text { (4-7 years of } \\
\text { sport } \\
\text { experience) }\end{array}$} & $\mathrm{HR}_{1}=58$ & $\mathrm{HR}_{2}=70$ & $\mathrm{HR}_{3}=55$ & \\
\hline & Sf & 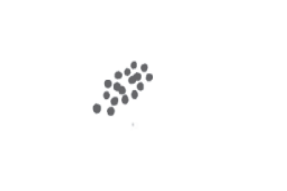 & :\% & 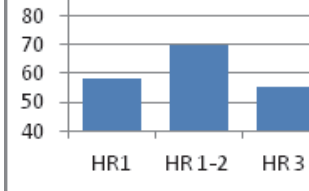 \\
\hline \multirow[b]{2}{*}{$\begin{array}{l}\text { Advanced } \\
\text { athletes }\end{array}$} & $\mathrm{HR}_{1}=48$ & $\mathrm{HR}_{2}=62$ & $\mathrm{HR}_{3}=45$ & \\
\hline & If & $\therefore \because$ & 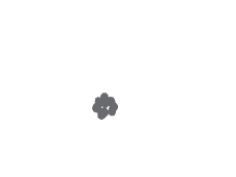 & $\begin{array}{lllll}80 & & & \\
70 & & & & \\
60 & & & & \\
50 & & & & \\
40 & & & & \\
& & \text { HR1 } & \text { HR 1-2 } & \text { HR3 }\end{array}$ \\
\hline
\end{tabular}


3. The Trendelenburg position during $3 \mathrm{~min}$.

4. Passive transition to supine position.

5. Supine (horizontal) position at rest during $3 \mathrm{~min}$.

When carrying out the functional antiorthostatic test background and transition and post transition periods of test records were under special attention.

Results and Discussion. All indicators which have a significant correlation with athlete's result were measured.

Heart rate increases from $62 \pm 6$ beats/min at rest to $65 \pm 7$ beats/min during head-down tilt, and then it decreases to $61 \pm 6$ beats/min. Heart rate has higher mean and standard deviation during transients $(71 \pm 10$ beats/min in head-down tilting, $65 \pm 7$ beats/min in returning).

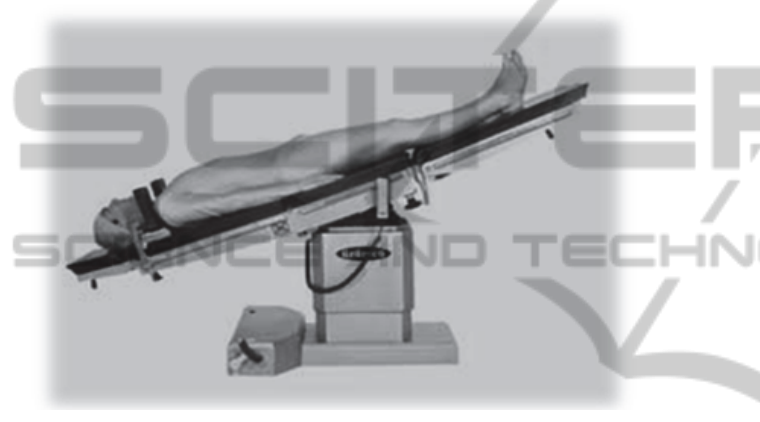

Figure 8: Trendelenburg position.

Subjects are more sensitive to the beginning of head-down tilt than to returning in primary position. The change in heart rate may be attributed to a decrease in stroke volume or increase of sympathetic tone (Lucia, 2000)

Table 2: Dynamics of hemodynamic indicators in the main position during antiorthostatic test.

\begin{tabular}{|l|c|c|c|}
\hline \multirow{2}{*}{ Indicator } & \multicolumn{3}{|c|}{ Mean $\pm \mathrm{SD}$} \\
\cline { 2 - 4 } & 1 & 3 & 5 \\
\hline $\mathrm{HR}$, beats $/ \mathrm{min}$ & $61 \pm 6$ & $67 \pm 9$ & $64 \pm 8$ \\
\hline $\mathrm{SV}, \mathrm{ml}$ & $102 \pm 16$ & $101 \pm 19$ & $98 \pm 18$ \\
\hline $\mathrm{SI}, \mathrm{ml} / \mathrm{m}^{2}$ & $60 \pm 5,6$ & $60 \pm 6,4$ & $60 \pm 6,1$ \\
\hline $\mathrm{EDV}, \mathrm{ml}$ & $162 \pm 30$ & $161 \pm 36$ & $158 \pm 31$ \\
\hline $\mathrm{EDI} \mathrm{ml} / \mathrm{m}^{2}$ & $98 \pm 11$ & $97 \pm 12$ & $97 \pm 10$ \\
\hline $\mathrm{CO}, \mathrm{l} / \mathrm{min}^{2}$ & $6,4 \pm 1,4$ & $6,8 \pm 1,6$ & $6,3 \pm 1,4$ \\
\hline $\mathrm{CI}, 1 / \mathrm{m}^{2}$ & $3,9 \pm 0,7$ & $4 \pm 0,7$ & $3,8 \pm 0,6$ \\
\hline SILVA, & $68 \pm 6,9$ & $67 \pm 11$ & $67 \pm 11,2$ \\
\hline
\end{tabular}

Stroke volume and end-diastolic volume (EDV) do not significantly fall from the $1^{\text {st }}$ position to the head-down tilt and continue decreasing in transient to supine position. At the same time indices (stroke index (SI), end-diastolic index (EDI) and stroke index of left ventricle activity (SILVA)) have minimal changes or no changes.
Cardiac output (CO) enhances from $6,1 \pm 4$ 1/min at rest to $6,8 \pm 1,7 \mathrm{l} / \mathrm{min}$ in antiorthostasis and decreases to $6,3 \pm 1,5 \mathrm{l} / \mathrm{min}$ in supine position after head-up tilt. During head-down tilting cardiac output is $6,6 \pm 1,6$ $1 / \mathrm{min}$, and when returning it increases to $6,9 \pm 1,7$ $1 / \mathrm{min}$. Magnitude of this indicator during test depends on heart rate change and stroke volume. Cardiac index is more sensible to position changes than other indices.

If there is considerable difference between the $1^{\text {st }}$ and the $5^{\text {th }}$ position, the athlete doesn't have a high fitness level. Perhaps overtraining or disease come into play. At the same time individual features influence is not excluded.

The indicator value in the $3^{\text {rd }}$ position shows cardiovascular and neural response to antiorthostatic load. If magnitudes exceed the normal value, inadequate response to workload takes place.

Table 3: Dynamics of hemodynamic indicators in the transients during antiorthostatic test.

\begin{tabular}{|l|c|c|}
\hline \multirow{2}{*}{ Indicator } & \multicolumn{2}{|c|}{ Mean \pm SD } \\
\cline { 2 - 3 } & 2 & 4 \\
\hline $\mathrm{HR}$, beats/min & $71 \pm 9$ & $67 \pm 8$ \\
\hline $\mathrm{SV}, \mathrm{ml}$ & $97 \pm 19,5$ & $100 \pm 22$ \\
\hline $\mathrm{SI}, \mathrm{ml} / \mathrm{m}^{2}$ & $58+7$ & $60+7,6$ \\
\hline $\mathrm{EDV}, \mathrm{ml}$ & $158 \pm 32$ & $161 \pm 34$ \\
\hline $\mathrm{EDI} \mathrm{ml} / \mathrm{m}^{2}$ & $94 \pm 11$ & $97 \pm 11$ \\
\hline $\mathrm{CO}, 1 / \mathrm{min}^{2}$ & $6,8 \pm 1,5$ & $6,7 \pm 1,5$ \\
\hline $\mathrm{CI}, \mathrm{l} / \mathrm{m}^{2}$ & $4,1 \pm 0,7$ & $4 \pm 0,6$ \\
\hline SILVA, & $65 \pm 9,4$ & $69 \pm 11$ \\
\hline
\end{tabular}

Hemodynamic indicators values have higher amplitude excursion during transients than in supine and head-up tilt because of adaptation to new body position. Too high changes of hemodynamic indicators point to inadequate response to workload or overtraining. However, too weak change or its absence shows adaptation problems which influence negatively the training process and competition results.

Thus hemodynamic response to antiorthostatic tests shows not only the fitness level of athletes, but the existence of diseases, overtraining and possible adaptation problems.

\section{CONCLUSIONS}

The state of the cardiorespiratory system and hemodynamics is an important criterion in achieving success in sport performance. That is why sport scientists should explore informative support technologies of athletes' functional diagnostics in 
order to supply sports practice with reliable information useful for planning the training process.

The use of hemodynamics monitor with impedance cardiography and spectrophotometry in base and comparing the obtained athletes' hemodynamics data with normal values of excellent athletes enable to detect individual features of athletes' physical workability, functional reserves or limiting factors of physical workability and predict athletic success and prospects for the sport.

Regular monitoring of athletes' hemodynamics allows to estimate the effectiveness of the training process, progress (or regress) of workability and suggest proper methods for its correction.

\section{REFERENCES}

Cooke, G., Marshall, P., Al-Timman, J., Wright, D., Riley, R., Hainsworth, R., Tan, L., 1998. Physiological cardiac reserve: development of a non-invasive method and first estimates in man. In Heart. Vol. 79, no. 3. pp. 289-294

Critoph, C., Patel, V., Mist, B., Thomas, Martin D., Elliott, P., 2013., Non-invasive assessment of cardiac output at rest and during exercise by finger plethysmography. In Clinical physiology and functional imaging. Vol. 33, no. 5. pp. 338-343

Delp, M., Evans, M., Duan, C., 1998. Effects of aging on cardiac output, regional blood flow, and body composition in Fischer-344 rats. In Journal of applied physiology. Vol. 85, no.5. pp. 1813-1822

Donina, J.A., 2011. Intersystem relations of breathing and blood circulation. In Human Physiology. Vol.37, no.2. pp.117-128.

Lucia, A., Hoyos, J., Perez, M., Chicharro J.L., 2000. Heart rate and performance parameters in elite cyclists: a longitudinal study. In Med.Sci.Sports Exerc. Vol.32. No.10, pp.1777-1782

Magder, S., 2014. Current tools for assessing heart function and perfusion adequacy. In Current opinion in critical care. Vol. 20, no.3. pp. 294-300

Newman, D., Callister, R., 1999. The non-invasive assessment of stroke volume and cardiac output by impedance cardiography: A review. In Aviation space and environmental medicine. Vol. 70, no. 8. pp. 780789

Pinsky, M., 2014. Functional haemodynamic monitoring. In Current opinion in critical care. Vol. 20, no. 3. pp. 288-293

Rowland, T., Lisowski, R., 2003. Determinants of diastolic cardiac filling during exercise. In Journal of Sports Medicine And Physical Fitness. Vol. 43, no. 3. pp. 380-385

Scharhag, J., Schneider, G., Urhausen, A., et al., 2002. Athlete's heart - Right and left ventricular mass and function in male endurance athletes and untrained individuals determined by magnetic resonance imaging. In Journal of the American college of cardiology. Vol. 40, no. 10. pp. 1856-1863

Seluyanov, V.N., 2002. Intuition is blind without knowledge, In Skiing Sport, Vol. 23. pp.62-67.

Stickland, M.K., Welsh, R.C., Petersen S.R., 2006. Does fitness level modulate the cardiovascular response to exercise? In J Appl Physiol. Vol.100, pp. 1895-1901

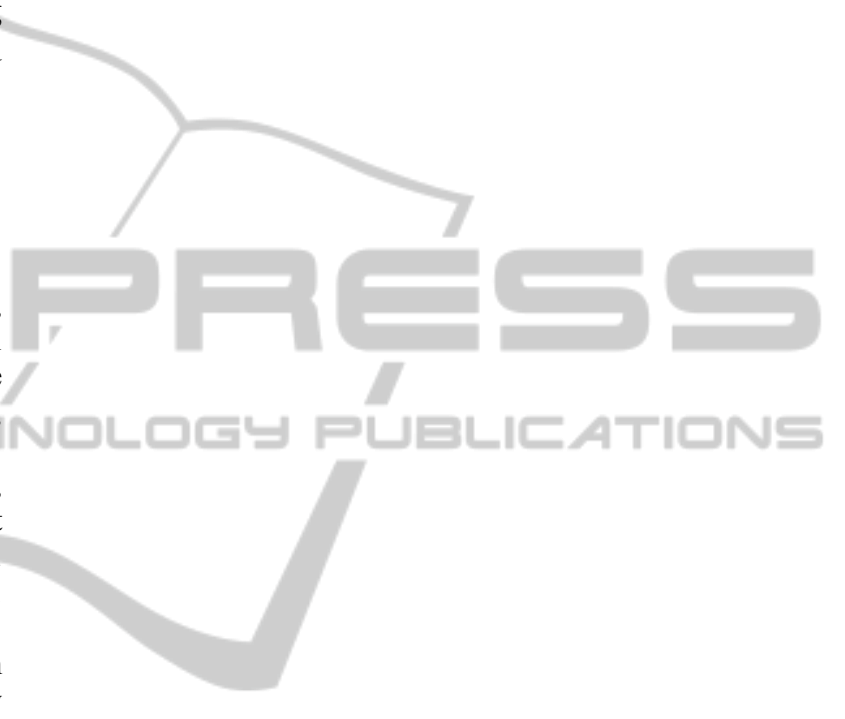

